\title{
High-performance liquid chromatography as a tool to evaluate the performance of the catalytic wet peroxide oxidation of 4-nitrophenol: pre-validation of analytical methods
}

\author{
Rui S. Ribeiro ${ }^{1}$, Adrián M. T. Silva² ${ }^{2}$ Helder T. Gomes ${ }^{3}$, Joaquim L. Faria ${ }^{4}$ \\ ${ }^{1}$ LCM - Laboratory of Catalysis and Materials - Associate Laboratory LSRE-LCM, Department of \\ Chemical and Biological Technology, School of Technology and Management, Polytechnic \\ Institute of Bragança, Campus de Santa Apolónia, 5300-857 Bragança, Portugal \\ (rui.ribeiro@ipb.pt); ${ }^{2}$ LCM - Laboratory of Catalysis and Materials - Associate Laboratory LSRE- \\ LCM, Departamento de Engenharia Química, Faculdade de Engenharia da Universidade do \\ Porto, Rua Dr. Roberto Frias, 4200-465 Porto, Portugal (adrian@fe.up.pt); ${ }^{3}$ LCM - Laboratory of \\ Catalysis and Materials - Associate Laboratory LSRE-LCM, Department of Chemical and \\ Biological Technology, School of Technology and Management, Polytechnic Institute of \\ Bragança, Campus de Santa Apolónia, 5300-857 Bragança (htgomes@ipb.pt); ${ }^{4}$ LCM - Laboratory \\ of Catalysis and Materials - Associate Laboratory LSRE-LCM, Departamento de Engenharia \\ Química, Faculdade de Engenharia da Universidade do Porto, Rua Dr. Roberto Frias, 4200-465 \\ Porto, Portugal (jlfaria@fe.up.pt)
}

\begin{abstract}
A high-performance liquid chromatography (HPLC) method capable to detect 4nitrophenol (4-NP) in aqueous solutions with concentration in the range 0.0495-118.8 mg L-1 was developed and validated under the typical criteria for in-house prevalidations. Accordingly, linearity was demonstrated through the Fisher's exact probability test. Accuracy and precision were then assessed in three concentration levels over the linear range.

The reproducibility of the catalytic wet peroxide oxidation (CWPO) of 4-NP was evaluated together with the analytical error of 4-NP determination in independent experiments. In this case, the sum of both contributions to error never reached $3 \%$. Two multi-component HPLC methods were also developed for the determination of possible aromatic intermediates (hydroquinone, 1,4-benzoquinone, catechol, 4nitrocatechol and phenol) and carboxylic acids (oxalic, formic, malic, malonic, acetic and maleic acids) resulting from the 4-NP degradation. The combination of these analytical methods already led to the proposal of an oxidation/mineralization mechanism for the CWPO of 4-NP.
\end{abstract}

Subject Headings. Chemical analysis, chromatography, water pollution.

Author Keywords. High-performance liquid chromatography (HPLC), catalytic wet peroxide oxidation (CWPO), 4-nitrophenol.

\section{Introduction}

Like other advanced oxidation processes, catalytic wet peroxide oxidation (CWPO) is a water treatment technology based on the in-situ generation of hydroxyl radicals $\left(\mathrm{HO}^{\circ}\right)$ - very reactive species with high oxidizing potential (between $+2.8 \mathrm{~V}$ and $+2.0 \mathrm{~V}$ ), known to be effective in the destruction of a huge range of organic pollutants (Gogate and Pandit 2004, Navalon, Alvaro and Garcia 2010). For that purpose, hydrogen peroxide $\left(\mathrm{H}_{2} \mathrm{O}_{2}\right)$ is used as oxidation source, provided that a suitable catalyst is employed to decompose $\mathrm{H}_{2} \mathrm{O}_{2}$ into $\mathrm{HO}^{\bullet}$ according to a previously reported reaction mechanism (Ribeiro et al 2013a). 
In recent years, CWPO has been well established as a treatment option that is suitable for the degradation of a broad range of toxic and bio-recalcitrant pollutants in aqueous phase (Bautista et al 2010, Domínguez et al 2014b, Lücking et al 1998, Melero et al 2009, Neamţu et al 2004, Pinho et al 2015, Ramirez et al 2007a, Rey et al 2008, Ribeiro et al 2012, Ribeiro et al 2013b, Santos et al 2009, Taran et al 2010). Although several studies have been focused on the degradation of real industrial wastewaters (Bautista et al 2010, Domínguez et al 2014b, Melero et al 2009), most CWPO applications still deal with model pollutants such as dyes (Neamţu et al 2004, Ramirez et al 2007b, Ribeiro et al 2012, Santos et al 2009), phenol (Pinho et al 2015, Rey et al 2008, Taran et al 2010) or other phenolic compounds (Lücking et al 1998, Ribeiro et al 2013b, Ribeiro et al 2015a). Typically, real effluents are complex mixtures of several compounds; therefore, generic (lumped) parameters such as chemical oxygen demand (COD) and/or total organic carbon (TOC) are usually determined in order to assess the efficiency of the CWPO treatment process (Bautista et al 2010, Domínguez et al 2014b, Melero et al 2009). On the other hand, model pollutants are usually prepared by dissolution of the target compound in water; in this case, to monitor the concentration of the model pollutant during the CWPO experiments, very specific analytical methods are required (Lücking et al 1998, Neamţu et al 2004, Pinho et al 2015, Ramirez et al 2007b, Rey et al 2008, Ribeiro et al 2012, Ribeiro et al 2013b, Santos et al 2009, Taran et al 2010). For that purpose, dyes have been usually determined by UV-Vis spectrophotometry (Neamţu et al 2004, Ramirez et al 2007b, Ribeiro et al 2012, Santos et al 2009), whereas high-performance liquid chromatography (HPLC) has been found as the most suitable analytical technique for the determination of phenol or phenolic compounds (Pinho et al 2015, Rey et al 2008, Ribeiro et al 2013b, Taran et al 2010).

In addition to the determination of the model compounds, HPLC techniques have been also used successfully in several works for the identification and quantification of reaction intermediates and by-products resulting from the degradation of the model pollutants by CWPO, allowing the identification of the oxidation/mineralization mechanisms that are involved in these processes (Domínguez et al 2013, 2014a, Inchaurrondo et al 2012, Rey et al 2008, Ribeiro et al 2015a).

The main goal of the present work is the development of a single-component HPLC analytical method suitable for the determination of 4-nitrophenol (4-NP), a compound chosen as model pollutant for the screening of new catalysts for CWPO. Once validated, this single-component method will allow to follow the 4-NP abatement during the CWPO experiments.

Furthermore, to perform the identification and quantification of reaction intermediates and by-products resulting from the degradation of 4-NP by CWPO, two other multi-component HPLC analytical methods were developed. Specifically, one of these multi-component methods is devoted to the determination of possible aromatic intermediates (i.e., hydroquinone, 1,4-benzoquinone, catechol, 4-nitrocatechol and phenol), whereas the other is focused on the determination of carboxylic acids (i.e., oxalic, formic, malic, malonic, acetic and maleic acids). Once validated, these multi-component methods allow the identification of the oxidation/mineralization mechanisms involved in the CWPO of 4-NP. Finally, in order to assess reproducibility and error of the 4-NP determinations in real applications, a suitable catalyst was synthesized and used in three consecutive CWPO runs. 
High-performance liquid chromatography as a tool to evaluate the performance of the catalytic wet peroxide oxidation of 4-nitrophenol

\section{Materials and Methods}

\subsection{Chemicals}

Catechol (99 wt.\%), 4-nitrocatechol (98 wt.\%), D-(+)-malic acid (99 wt.\%), maleic acid (99 wt.\%), sulfuric acid $\left(\mathrm{H}_{2} \mathrm{SO}_{4}, 95-97 \mathrm{wt} . \%\right)$ and hydrogen peroxide $\left(\mathrm{H}_{2} \mathrm{O}_{2}, 30 \% \mathrm{w} / \mathrm{v}\right)$ were obtained from Fluka. 4-nitrophenol (4-NP, 99 wt.\%) and 1,4-benzoquinone (99 wt.\%) were purchased from Acros Organics. Phenol (99.5 wt.\%), formic acid (98 wt.\%) and sodium hydroxide ( $\mathrm{NaOH}, 98$ wt.\%) were obtained from Panreac. Hydrochloric acid ( $\mathrm{HCl}, 37$ wt.\%), oxalic acid (99 wt.\%) and malonic acid (99 wt.\%) were purchased from Sigma-Aldrich and hydroquinone (99 wt.\%) was obtained from Merck. Methanol (HPLC grade, 99.99 wt.\%), glacial acetic acid (99.83 wt.\%) and acetonitrile (HPLC grade, 99.99 wt.\%) were obtained from Fisher Chemical.

All chemicals were used as received without further purification. Distilled water was used throughout the work.

\subsection{Standards}

The experimental work required for the development and validation of the analytical methods was performed using standard samples (Std.) with previously known concentrations. All the Std. were prepared considering the purity of each compound (cf. Section 2.1) and injected in triplicate. The accurate concentration of each Std. is given in Table 1.

\subsection{Analytical methods}

UV-Vis absorption spectra were obtained using a T70 Spectrophotometer (PG Instruments, Ltd.) in the wavelength range of 200-660 nm, with a scan interval of $1 \mathrm{~nm}$.

The amount of 4-NP was determined by HPLC, adapting the procedure described elsewhere (Apolinário et al 2008). For that purpose, a Jasco HPLC system equipped with an UV-Vis detector (UV-2075 Plus), a quaternary gradient pump (PU-2089 Plus) for solvent delivery (1

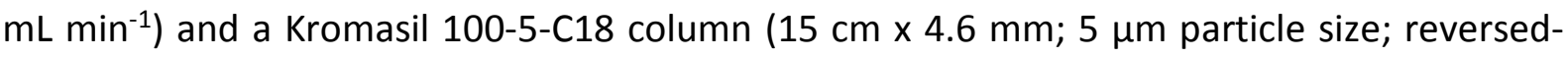
phase) was employed. Mobile phase consisted in an isocratic method of $A: B$ (40:60) mixture of $3 \%$ acetic acid and $1 \%$ acetonitrile in methanol (A) and $3 \%$ acetic acid in ultrapure water (B). The 4-NP absorbance peaked at $318 \mathrm{~nm}$, as determined from the corresponding UV-Vis absorption spectrum. Possible intermediates of 4-NP oxidation (e.g., hydroquinone, 1,4benzoquinone, 4-nitrocatechol, catechol and phenol) were determined using the same system, the absorbance wavelength being adjusted to $277 \mathrm{~nm}$.

The amount of the carboxylic acids (e.g., formic, acetic, oxalic, malonic, maleic and malic acids) was also determined using the same Jasco HPLC system, but in this case using an YMC - Triart C18 column ( $25 \mathrm{~cm} \times 4.6 \mathrm{~mm} ; 5 \mu \mathrm{m}$ particle size; reversed-phase), adapting procedures reported elsewhere (Rocha et al 2011, Yang et al 2000). Mobile phase consisted in an isocratic method of $A: B(95: 5)$ mixture of $1 \%$ sulfuric acid in ultrapure water $(A)$ and acetonitrile (B), delivered to the system at $0.6 \mathrm{~mL} \mathrm{~min}{ }^{-1}$. The UV/Vis detector was set to $210 \mathrm{~nm}$.

\subsection{Synthesis of the catalyst}

The catalyst used in the CWPO experiments was prepared by polycondensation of resorcinol with formaldehyde (with a molar ratio of 1:2), adapting a procedure previously reported (Gomes et al 2008). Namely, $9.91 \mathrm{~g}$ of resorcinol were added to $18.8 \mathrm{~mL}$ of deionized water in a glass flask, to which a calculated mass of iron (III) chloride hexahydrate was added (Fe/resorcinol molar ratio of 0.05 ). After complete dissolution, $13.5 \mathrm{~mL}$ of formaldehyde solution were also added. In order to achieve the desired initial $\mathrm{pH}$ of the precursor solution (6.1), sodium hydroxide solution was added dropwise under continuous stirring and $\mathrm{pH}$ 
monitoring. The gelation step was allowed to proceed at $85^{\circ} \mathrm{C}$ during 3 days. After this period the gel was dried in oven during several days from 60 to $150{ }^{\circ} \mathrm{C}$, defining a heating ramp of $20^{\circ} \mathrm{C} \mathrm{Cay}^{-1}$. After drying, the gel was calcined under a nitrogen flow $\left(100 \mathrm{~cm}^{3} \mathrm{~min}^{-1}\right)$ at 120,400 and $600{ }^{\circ} \mathrm{C}$ during $60 \mathrm{~min}$ at each temperature and then at $800^{\circ} \mathrm{C}$ for $240 \mathrm{~min}$, defining a heating ramp of $2^{\circ} \mathrm{C} \mathrm{min}{ }^{-1}$. Finally, the calcined materials were washed with $1 \mathrm{~L}$ of deionized water at $50^{\circ} \mathrm{C}$ under vacuum filtration, and then with $1 \mathrm{~L}$ of $\mathrm{HCl}$ solution $(\mathrm{pH}=3)$, also at $50^{\circ} \mathrm{C}$ under vacuum filtration, being afterwards dried overnight in an oven at $60^{\circ} \mathrm{C}$, resulting in the material named $\mathrm{CX} / \mathrm{Fe}_{0.05}$.

\begin{tabular}{|c|c|c|c|c|c|c|c|c|}
\hline \multirow{2}{*}{ Analyte } & \multicolumn{8}{|c|}{ Std. concentration ( $\mathrm{mg} \mathrm{L}^{-1}$ ) } \\
\hline & $\# 1$ & $\# 2$ & \#3 & $\# 4$ & \#5 & $\# 6$ & $\# 7$ & \#8 \\
\hline 4-NP & $0.0495^{a}$ & 19.8 & $39.6^{b}$ & 79.24 & $118.8^{c}$ & - & - & \\
\hline Hydroquinone & $0.0449^{a}$ & 4.49 & 22.4 & $89.7^{b}$ & $179^{c}$ & - & - & - \\
\hline 1,4-Benzoquinone & $0.0892^{a}$ & 0.892 & 44.6 & $89.2^{b}$ & 178 & $357^{c}$ & - & - \\
\hline Catechol & 0.0468 & $0.0936^{a}$ & 0.936 & 9.36 & 46.8 & $93.6^{c}$ & - & - \\
\hline 4-Nitrocatechol & 0.0445 & $0.0890^{a}$ & 8.90 & 44.5 & $89.0^{\mathrm{b}}$ & 178 & $356^{c}$ & - \\
\hline Phenol & 0.0456 & $0.0911^{\mathrm{a}}$ & 0.911 & 9.11 & 45.6 & $91.1^{c}$ & - & - \\
\hline Oxalic acid & $10.2^{\mathrm{a}}$ & 20.3 & 40.7 & 81.4 & $163^{c}$ & - & - & - \\
\hline Formic acid & $10.1^{a}$ & 20.2 & 40.3 & 80.7 & $161^{b}$ & $323^{c}$ & - & - \\
\hline Malic acid & $20.7^{a}$ & 41.4 & 82.8 & 166 & $332^{b}$ & $663^{c}$ & 1327 & - \\
\hline Malonic acid & $22.7^{\mathrm{a}}$ & 45.5 & 182 & $364^{b}$ & $728^{c}$ & 1456 & - & - \\
\hline Acetic acid & $13.5^{\mathrm{a}}$ & 26.9 & 53.9 & 108 & $216^{b}$ & $431^{c}$ & - & - \\
\hline Maleic acid & 0.0989 & $0.198^{a}$ & 0.989 & 1.98 & 3.96 & 7.92 & $15.8^{b}$ & $31.7^{\circ}$ \\
\hline
\end{tabular}

Table 1: Concentration of the standard samples (Std.) used throughout the work. a, $\mathrm{b}$ and $\mathrm{c}$ Standards used in the validation studies: (a) low, (b) medium and (c) high concentration levels over the working range

\subsection{CWPO experiments}

Batch CWPO experiments were performed as previously described (Ribeiro et al 2015a), in a $250 \mathrm{~mL}$ well-stirred $(600 \mathrm{rpm})$ glass reactor equipped with a condenser, a temperature measurement thermocouple, a pH measurement electrode and a sample collection port. The reactor was loaded with $50 \mathrm{~mL}$ of a 4-NP aqueous solution $\left(5.0 \mathrm{~g} \mathrm{~L}^{-1}\right)$ and heated by immersion in an oil bath at controlled temperature. Upon stabilization at the desired temperature, the solution $\mathrm{pH}$ was adjusted to 3 by means of $\mathrm{H}_{2} \mathrm{SO}_{4}$ and $\mathrm{NaOH}$ solutions, and the experiments were allowed to proceed freely, without further $\mathrm{pH}$ adjustment. A calculated volume of $\mathrm{H}_{2} \mathrm{O}_{2}$ $(30 \% \mathrm{w} / \mathrm{v})$ was injected into the system, in order to reach the stoichiometric amount of $\mathrm{H}_{2} \mathrm{O}_{2}$ needed to completely mineralize 4-NP $\left(17.8 \mathrm{~g} \mathrm{~L}^{-1}\right)$. The catalyst $\left(\mathrm{CX} / \mathrm{Fe}_{0.05}\right.$, cf. Section 2.4) was added after complete homogenization of the resulting solution, that moment being considered as $t_{0}=0 \mathrm{~min}$. The experiments were conducted during $24 \mathrm{~h}$, at $\mathrm{T}=50{ }^{\circ} \mathrm{C}, \mathrm{pH}=3$ and catalyst load $=2.5 \mathrm{~g} \mathrm{~L}^{-1}$.

\section{Acceptance criteria for methods validation}

Based on a literature survey, acceptance criteria were established for each one of the parameters that were considered in this in-house validation (cf. Table 2). Individual expressions and requirements for each parameter are detailed in the next subsections.

It should be noted that the ruggedness of the analytical methods was not assessed since the experimental work was fully performed by the same operator and using the same equipment.

\subsection{Accuracy}

The difference between the true value $\left(X_{\text {true }}\right)$ and the measured value $\left(X_{\text {measured }}\right)$ was assessed through the analysis of bias values obtained as described in Eq. 1 (Taverniers, De Loose and Van Bockstaele 2004). The values of $X_{\text {measured }}$ were given by the average result obtained by 
three replicate measurements of three samples over the working range, representing high, medium and low concentration levels (cf. Table 1), as typically required (Snyder, Kirkland and Glajch 1997, Taverniers, De Loose and Van Bockstaele 2004).

In the particular case of bias, the results obtained should be compared with a second validated reference method (Taverniers, De Loose and Van Bockstaele 2004). Therefore, since no validated reference methods were found, the acceptance criterion was established as $20 \%$, i.e., the accuracy of the analytical method is accepted if the absolute value of bias is $\leq 20 \%$ (Peters and Maurer 2005, UNODC 2009, USEPA 1997).

$$
\text { bias, } \%=\frac{\left(X_{\text {measured }}-X_{\text {true }}\right)}{X_{\text {true }}} \times 100
$$

\subsection{Precision}

During the pre-validation of the methods, only repeatability precision and intermediate precision were assessed, since these are the levels of precision that are usually related to measurements performed within the same laboratory (Snyder, Kirkland and Glajch 1997, Taverniers, De Loose and Van Bockstaele 2004). Both levels of precision were expressed in terms of relative standard deviation (RSD, also known as coefficient of variation) of a data set, as usually performed (Snyder, Kirkland and Glajch 1997, Taverniers, De Loose and Van Bockstaele 2004). In repeatability precision (i.e., intra-run precision) conditions, three samples over the working range, representing high, medium and low concentration levels (cf. Table 1), were independently measured in triplicate assays during one day; in intermediate precision (i.e., inter-run precision) conditions, that same three samples were independently measured in triplicate assays during three consecutive days, as typically required (Snyder, Kirkland and Glajch 1997, Taverniers, De Loose and Van Bockstaele 2004). Afterwards, the RSD associated to repeatability precision ( $\mathrm{RSD}_{\mathrm{r}}$ ) was obtained as described in Eq. 2, while RSD associated to intermediate precision ( $R S D_{\text {int }}$ ) was obtained as described in Eq. 3 (Taverniers, De Loose and Van Bockstaele 2004). SD $_{r}$ is the standard deviation (SD) obtained in repeatability precision conditions and $\mathrm{SD}_{\text {int }}$ is the SD obtained in intermediate precision conditions; $\tilde{\mathrm{X}}$ is the average of the measured values.

$$
\begin{aligned}
& \mathrm{RSD}_{r}, \%=\frac{\mathrm{SD}_{\mathrm{r}}}{\tilde{\mathrm{X}}} \times 100 \\
& \mathrm{RSD}_{\text {int }}, \%=\frac{\mathrm{SD}_{\text {int }}}{\tilde{\mathrm{X}}} \times 100
\end{aligned}
$$

Nowadays, the so-called Horwitz ratio (HorRat) is widely recognized as a suitable acceptance criterion for the evaluation of the precision of an analytical method, namely by several research groups (Brown and Yu 2013, Indyk et al 2014, Sasaki et al 2014) and organizations worldwide (Horwitz and Albert 2006, Latimer 2012). Specifically, the HorRat is a normalized performance parameter indicating the acceptability of the precision of an analytical method, which is obtained by the ratio between the observed RSD and the predicted relative standard deviation (PRSD) calculated from the Horwitz equation, as described in Eq. 4 (Horwitz and Albert 2006). PRSD is obtained as described in Eq. 5 , where $C$ is the concentration of a given analyte, expressed as a dimensionless mass fraction (Horwitz and Albert 2006, Latimer 2012).

$$
\begin{aligned}
& \text { HorRat }=\frac{\text { RSD }}{\text { PRSD }} \\
& \text { PRSD }=2 C^{-0.15}
\end{aligned}
$$

Based on recommendations made by AOAC International - Association of Official Analytical Chemists, regarding standard method performance requirements, the optimum target for 
HorRat values should be set to 0.5 in validations performed within the laboratory (Latimer 2012). Nevertheless, a broader acceptance criterion has been defined by the same organization considering HorRat values of 0.3 and 1.3 as the minimum and maximum acceptance values, respectively (Latimer 2012). Therefore, these values were used to set the HorRat acceptance criterion used in this work for repeatability precision (HorRat ${ }_{r}$ ) and intermediate precision (HorRatint).

\begin{tabular}{cl} 
Parameter & Requirement/ description \\
\hline Accuracy & $\mid$ bias $\mid \leq 20 \%$ \\
Precision & HorRat $\leq 1.3$ \\
Linearity & $\mathrm{P}\left(\mathrm{H}_{0,2 n d}\right)>0.05$ \\
Range & Lower and upper analyte concentrations for which the analytical \\
& method has adequate accuracy, precision and linearity \\
LOD & $\begin{array}{l}\text { Determined based on the average peak area of } 10 \text { independent } \\
\text { blank samples, plus } 3 \text { times the corresponding standard deviation }\end{array}$ \\
& Determined based on the average peak area of 10 independent \\
& blank samples, plus 10 times the corresponding standard deviation \\
\hline
\end{tabular}

Table 2: Acceptance criteria considered in this work

\subsection{Linearity and range}

Statistical tests, such as the Lack-of-fit test, the Mandel's fitting test or the Fisher's exact test, are the more suitable options for the validation of a linear calibration model (Fisher 1934, Loco et al 2002). In this work, Fisher's exact probability test was used to assess the linearity of the calibration curves (Fisher 1934). Specifically, the data was adjusted to a second-degree polynomial model $\left(y=\beta_{0}+\beta_{1} x+\beta_{2} x^{2}\right)$, and then the statistical significance of the null value of the second-degree coefficient was tested through its $p$-value $\left[P\left(H_{0,2 n d}\right)\right]$, with a significance level of $\mathrm{P} \leq 0.05$. Therefore, the acceptance criterion for the linearity of the calibration curve was set to $\mathrm{P}\left(\mathrm{H}_{0,2 \text {,nd }}\right)>0.05$.

The question of whether to force the regression line through the origin (i.e., $\beta_{0}=0$ ) has been the subject of several debates on linear regression (Meier and Zünd 2000). Although theory can justify the $\beta_{0}=0$ assumption, the reality may be somewhat more complex (Meier and Zünd 2000). Taking this into account, the statistical significance of the null value of the $y$ intercept was tested through its $p$-value $\left[P\left(H_{0, i n t}\right)\right]$, with a significance level of $P \leq 0.05$. Therefore, a linear model with $y$-intercept $\left(y=\beta_{0}+\beta_{1} x\right)$ was used when $P\left(H_{0}\right.$,int $) \leq 0.05$, whereas a linear model without $y$-intercept $\left(y=\beta_{1} x\right)$ was used when $P\left(H_{0, \text { int }}\right)>0.05$.

All the linear and polynomial regressions were performed using $\mathrm{R}$ Software (version 3.1.2), Copyright (C) 2014, The R Foundation for Statistical Computing.

The range of each method was defined as the lower and upper analyte concentrations for which the analytical method has adequate accuracy, precision and linearity (Snyder, Kirkland and Glajch 1997).

\subsection{Limit of detection}

The determination of the limit of detection (LOD) of each analyte was based on a signal-tonoise ratio of 3, as suggested by Eurachem and IUPAC (Snyder, Kirkland and Glajch 1997, Taverniers, De Loose and Van Bockstaele 2004). The practical assessment of these values was performed as previously described (Taverniers, De Loose and Van Bockstaele 2004). Namely, 10 independent blank samples were analyzed, in order to determine the average peak area of 
that samples $\left(\mathrm{x}_{\mathrm{bl}}\right)$ and the corresponding standard deviation $\left(\mathrm{s}_{\mathrm{bl}}\right)$. Afterwards, the LOD value was obtained as described in Eq. 6 , where $\beta_{1}$ is the slope of the linear regression performed for the quantification of each component.

$$
\operatorname{LOD}=\frac{x_{b l}+3 s_{b l}}{\beta_{1}}
$$

\subsection{Limit of quantification}

The limit of quantification (LOQ) of each analyte was determined exactly as in the case of the LOD, except that it was based on a signal-to-noise ratio of 10, as described in Eq. 7 (Snyder, Kirkland and Glajch 1997, Taverniers, De Loose and Van Bockstaele 2004).

$$
\mathrm{LOQ}=\frac{\mathrm{x}_{\mathrm{bl}}+10 \mathrm{~s}_{\mathrm{bl}}}{\beta_{1}}
$$

\section{Results and discussion}

\subsection{Development and validation of the analytical methods}

In this Section, the development of three distinct and independent analytical methods will be described and discussed. Furthermore, the resulting methods will undergo in-house validation studies.

\subsubsection{Selection of the HPLC method}

The first task of the development process was the choice of the most accurate HPLC method. Accordingly, taking into account that 4-NP, the aromatic intermediates and carboxylic acids considered in this work are non-ionic compounds soluble in water, reversed-phase HPLC was found the most appropriate solution (Lindsay 1992). For each particular analytical method, the choice of the most suitable reversed-phase HPLC column was made based on procedures previously reported elsewhere. Namely, a Kromasil 100-5-C18 column was used for 4-NP and for aromatic intermediates determinations (Apolinário et al 2008), whereas a YMC-Triart C18 column was used for carboxylic acids determination (Rocha et al 2011).

\subsubsection{Selection of the detector}

The next step in the development process was the selection of the most appropriate detector. It is known that UV-Vis detectors are by far the most used in HPLC (Christian 1994, Lindsay 1992), mainly due to their high sensitivity, relatively low cost and robustness towards slight temperature changes (Christian 1994). Furthermore, UV-Vis detectors are selective, since they only detect compounds that absorb a specific UV or visible radiation (Lindsay 1992). Keeping these assumptions in mind, an UV-Vis detector was chosen (Jasco UV-2075 Plus). Afterwards, UV-Vis absorbance spectra were obtained for each component, using a spectrophotometer (cf. Section 2.3). UV-Vis detector settings (i.e., appropriate absorbance wavelengths) were then selected based on the resulting spectra, which are shown in Figure 1.

It should be mentioned that the three analytical methods will be employed to the analysis of complex samples containing 4-NP, and possibly several aromatic intermediates and carboxylic acids. Therefore, the wavelength of each method should be set to a value in which potential interferences have minimal absorbance (Snyder, Kirkland and Glajch 1997). Keeping this in mind, it is observed in Figure 1a that the absorbance spectrum of 4-NP has a very well pronounced maximum at $318 \mathrm{~nm}$. On the opposite, the aromatic intermediates and the carboxylic acids all have negligible absorbance at that wavelength, except 4-nitrocatechol, as it can be seen in Figures $1 \mathrm{~b}$ and $\mathrm{c}$. Therefore, the UV-Vis detector wavelength was set to 318 $\mathrm{nm}$ in the analytical method developed for the determination of 4-NP. The analysis of the UVVis absorbance spectra of the aromatic intermediates is more complex, since several 
compounds must be simultaneously determined. As observed in Figure $1 \mathrm{~b}$, several of these aromatic intermediates have their maximum absorbance peak around $220 \mathrm{~nm}$ and/or around $277 \mathrm{~nm}$. On the other hand, as seen in Figure 1c, most of the carboxylic acids also show maximum absorbance around $220 \mathrm{~nm}$, but negligible absorbance at $277 \mathrm{~nm}$. Therefore, in order to minimize possible interferences from carboxylic acids, the UV-Vis detector wavelength was set to $277 \mathrm{~nm}$ in the analytical method developed for the determination of aromatic intermediates. Finally, the UV-Vis detector wavelength was set to $210 \mathrm{~nm}$ in the analytical method developed for the determination of carboxylic acids, in this way minimizing possible interferences from aromatic intermediates. Nevertheless, it should also be mentioned at this point that possible interferences only occur with overlapped compounds (i.e. compounds leaving the HPLC column with the same retention time). Therefore, the selection of the mobile phase for the determination of carboxylic acids also takes this into consideration.

\subsubsection{Selection of the mobile phase}

Once the detector settings were selected, the mobile phase and the way the mobile phase is supplied to the system were also selected. A combination of mobile phase and mobile phase rate, which was initially reported for the determination of dinitrophenol and trinitrophenol (Apolinário et al 2008) was successfully adapted for the determination of 2-nitrophenol by our group (Ribeiro et al 2013b, Ribeiro et al 2015b). That adaptation was used with success in a preliminary run for the determination of 4-NP, thus being selected for the analytical method used for the determination of 4-NP. Specifically, the mobile phase consists in an isocratic method of $A: B(40: 60)$ mixture of $3 \%$ acetic acid and $1 \%$ acetonitrile in methanol $(A)$ and $3 \%$ acetic acid in ultrapure water (B), delivered at $1 \mathrm{~mL} \mathrm{~min}^{-1}$. Furthermore, this mobile phase also showed good performance when applied to the determination of aromatic intermediates. In this case, complete separation of the individual components in the mixture was achieved, as observed by the high resolution of the resulting chromatographic peaks (as confirmed by the retention times given in Table 3). On the other hand, the development of a combination of mobile phase and mobile phase rate, suitable for carboxylic acids determination, was slightly more complex. Both the mobile phase and the mobile phase rate had to be optimized through a systematic approach in which each parameter was individually assessed. In a first preliminary run, the mobile phase consisted in a sulfuric acid solution ( $4 \mathrm{mmol} \mathrm{L}^{-1}$ ) delivered at flow rate of $0.6 \mathrm{~mL} \mathrm{~min} \mathrm{~m}^{-1}$ (Rocha et al 2011). This combination did not allowed proper separation of the mixture components. Therefore, different sulfuric acid concentrations (in the range 4-200 $\mathrm{mmol} \mathrm{L}^{-1}$ ) and delivery rates (in the range $0.4-1 \mathrm{~mL} \mathrm{~min}^{-1}$ ) were tested. None of the tested combinations resulted in a suitable separation of the mixture components. In the second approach, a mobile phase consisting in an isocratic method of $A: B(95: 5)$ mixture of $1 \%$ sulfuric acid in ultrapure water $(A)$ and acetonitrile $(B)$, delivered to the system at 0.8 $\mathrm{mL} \min ^{-1}$ (Yang et al 2000), was tested. This time, the resulting separation of the mixture components was better. Thus, distinct sulfuric acid concentrations (in the range 20-200 mmol $\mathrm{L}^{-1}$ ) and delivery rates were tested (in the range 0.4-1 $\mathrm{mL} \mathrm{min}^{-1}$ ). The best separation was obtained when using a delivery rate of $0.6 \mathrm{~mL} \mathrm{~min}^{-1}$ and the composition which was previously reported by Yang et al. (Yang et al 2000). As observed by the retention times given in Table 3, complete separation of the individual components in the mixture was achieved in this way.

\subsubsection{Quantitative determination}

Assuming that the separation conditions were fully optimized for each analytical method, the next step was the quantitative analysis of each component. Within this scope, the peak area 
was used in order to provide a value in terms of detector signal; this signal being then related to the concentration of the respective analyte through linear calibration curves (Snyder, Kirkland and Glajch 1997). The number of standards that were used for each calibration, the retention times, the linear ranges, the linear fitting parameters, the statistical significance of the null value of the $y$-intercepts $\left[P\left(\mathrm{H}_{0}\right.\right.$, int $\left.)\right]$, and the statistical significance of the null value of the second-degree coefficients $\left[\mathrm{P}\left(\mathrm{H}_{0,2 n d}\right)\right]$, are given in Table 3. As detailed in Section 3.1.3, a linear model without $y$-intercept was used when $\mathrm{P}\left(\mathrm{H}_{0, \text { int }}\right)>0.05$ and the non-linearity of the calibration curve was found insignificant when $\mathrm{P}\left(\mathrm{H}_{0,2 \mathrm{nd}}\right)<0.05$. Therefore, the linear range was demonstrated for all the analytes.

\subsubsection{Limit of detection and limit of quantification}

The limit of detection (LOD) and the limit of quantification (LOQ) of each analyte, obtained as described in Sections 3.4 and 3.5, respectively, are given in Table 4. As observed, 4-NP presents the lowest LOD and LOQ values, whereas the carboxylic acids have the highest limits.

\subsubsection{Precision and bias studies}

Precision and bias studies may be considered the most important criteria for the validation of analytical methods (Taverniers, De Loose and Van Bockstaele 2004). Therefore, bias was determined for three concentration levels over the linear range, as recommended (Snyder, Kirkland and Glajch 1997, Taverniers, De Loose and Van Bockstaele 2004). The corresponding results are also given in Table 4. For more details on the exact concentrations that were used for bias determinations, please refer to Table 1. As observed in Table 4, all the values of bias are in accordance with the acceptance criterion that was established in Section 3.1 (i.e., absolute value of bias $\leq 20 \%$ ).

As described in Section 3.2, repeatability precision (i.e., intra-run precision) and intermediate precision (i.e., inter-run precision) were assessed in three concentration levels over the linear range, through the so-called Horwitz ratio (HorRat). For more details on the exact concentrations that were used in the precision studies, please refer to Table 1 . The results obtained in repeatability precision conditions (HorRat ${ }_{r}$ ) and in intermediate precision conditions (HorRatint), are shown in Figures 2 and 3 , respectively. As observed, all the HorRat ${ }_{r}$

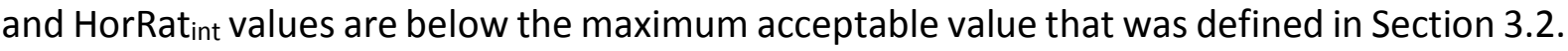
Summarizing, the accuracy and precision criteria were met in all the concentration levels that were considered. Therefore, considering the criteria established in Section 3.3 for the definition of the range of each analytical method, it can be concluded that all the analytical methods were validated in the linear range of each analyte. 

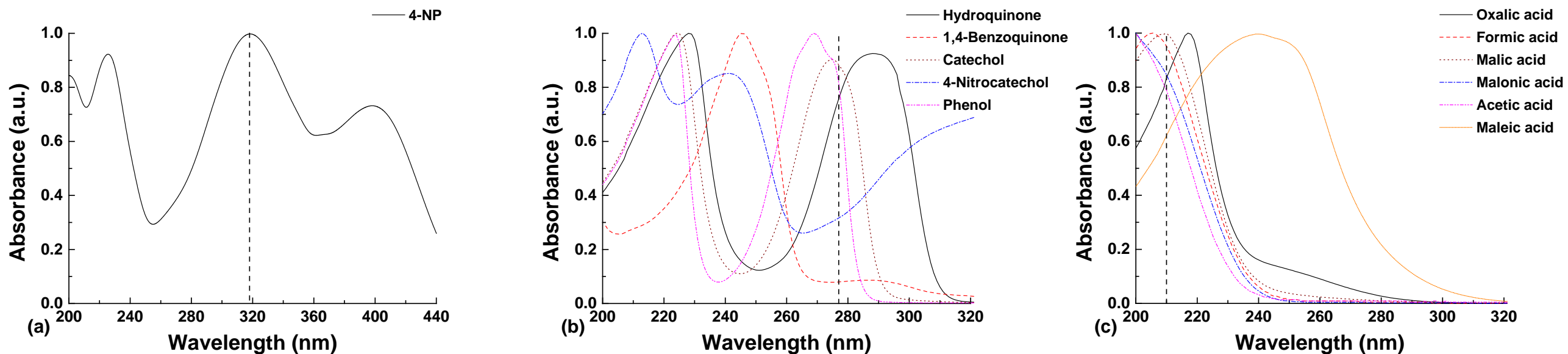

Figure 1: UV-VIS absorbance spectra of (a) 4-nitrophenol (4-NP), (b) aromatic intermediates (hydroquinone, 1,4-benzoquinone, catechol, 4-nitrocatechol and phenol) and (c) carboxylic acids (oxalic, formic, malic, malonic, acetic and maleic acids), obtained as described in Section 2.3. Vertical line points out the

wavelengths selected for each determination: (a) $318 \mathrm{~nm}$, (b) $277 \mathrm{~nm}$ and (c) $210 \mathrm{~nm}$

\begin{tabular}{|c|c|c|c|c|c|c|c|c|}
\hline \multirow{2}{*}{ Analyte } & \multirow{2}{*}{$\begin{array}{l}\text { Retention time } \\
\text { (min) }\end{array}$} & \multirow{2}{*}{ Std. } & \multirow{2}{*}{$\begin{array}{l}\text { Linear range } \\
\left(\mathrm{mg} \mathrm{L}^{-1}\right)\end{array}$} & \multicolumn{4}{|c|}{ Linear fitting } & \multirow{2}{*}{$P\left(H_{0,2 n d}\right)$} \\
\hline & & & & y-intercept & $P\left(H_{0, \text { int }}\right)$ & Slope & $r^{2}$ & \\
\hline 4-NP & $8.6 \pm 0.1$ & 5 & $0.0495-118.8$ & 0 & 0.615 & 71692.6 & 1 & 0.170 \\
\hline Hydroquinone & $1.981 \pm 0.007$ & 5 & $0.0449-179$ & 0 & 0.288 & 17829.3 & 0.9993 & 0.063 \\
\hline 1,4-benzoquinone & $2.64 \pm 0.01$ & 6 & $0.0892-357$ & 0 & 0.149 & 4696.3 & 0.9997 & 0.134 \\
\hline Catechol & $3.19 \pm 0.02$ & 6 & $0.0468-93.6$ & 0 & 0.308 & 24851.8 & 1 & 0.388 \\
\hline 4-nitrocatechol & $5.17 \pm 0.09$ & 7 & $0.0445-356$ & 0 & 0.136 & 15410.8 & 1 & 0.245 \\
\hline Phenol & $5.61 \pm 0.07$ & 6 & $0.0456-91.1$ & 0 & 0.434 & 15148.4 & 1 & 0.919 \\
\hline Oxalic acid & $5.45 \pm 0.02$ & 5 & $10.2-163$ & -7925.3 & 0.006 & 11992.8 & 1 & 0.170 \\
\hline Formic acid & $5.79 \pm 0.01$ & 6 & $10.1-323$ & 0 & 0.593 & 2043.2 & 0.9999 & 0.104 \\
\hline Malic acid & $6.25 \pm 0.04$ & 7 & $20.7-1327$ & 0 & 0.974 & 1674.1 & 0.9998 & 0.105 \\
\hline Malonic acid & $7.13 \pm 0.05$ & 6 & $22.7-1456$ & 16389.5 & 0.007 & 1716.6 & 1 & 0.419 \\
\hline Acetic acid & $7.54 \pm 0.02$ & 6 & $13.5-431$ & 0 & 0.065 & 729.1 & 0.9997 & 0.401 \\
\hline Maleic acid & $9.6 \pm 0.1$ & 8 & $0.0989-31.7$ & -3166.7 & 0.007 & 109423.4 & 1 & 0.804 \\
\hline
\end{tabular}

Table 3: Retention times and calibration data of each analyte (number of standards used throughout the linear range, linear fitting parameters and $p$-values calculated using the Fisher's exact test) 


\begin{tabular}{cccccc}
\hline Analyte & LOD $\left(\mathrm{mg} \mathrm{L}^{-1}\right)$ & LOQ $\left(\mathrm{mg} \mathrm{L}^{-1}\right)$ & \multicolumn{3}{c}{ bias (\%) } \\
& & & Low & Medium & High \\
\hline 4-NP & 0.0018 & 0.0049 & 10.39 & -0.47 & 0.36 \\
\hline Hydroquinone & 0.0082 & 0.023 & 14.98 & 3.22 & -1.02 \\
1,4-benzoquinone & 0.031 & 0.086 & -15.55 & 4.02 & -0.63 \\
Catechol & 0.0059 & 0.016 & -0.15 & n.a. & -0.04 \\
4-nitrocatechol & 0.0095 & 0.026 & -19.25 & 0.50 & -0.04 \\
Phenol & 0.0097 & 0.027 & -0.60 & n.a. & 0.00 \\
\hline Oxalic acid & 0.19 & 0.60 & 11.32 & n.a. & 0.04 \\
Formic acid & 1.1 & 3.5 & 0.24 & 1.44 & -0.36 \\
Malic acid & 1.4 & 4.3 & -11.24 & 4.54 & 0.86 \\
Malonic acid & 1.3 & 4.2 & 0.62 & 0.44 & -0.72 \\
Acetic acid & 3.2 & 9.9 & 8.56 & 0.57 & 0.13 \\
Maleic acid & 0.021 & 0.066 & 1.29 & 0.03 & 0.00 \\
\hline
\end{tabular}

Table 4: Limit of detection (LOD), limit of quantification (LOQ) and bias obtained for each analyte, in low, medium and high concentration levels over the linear range

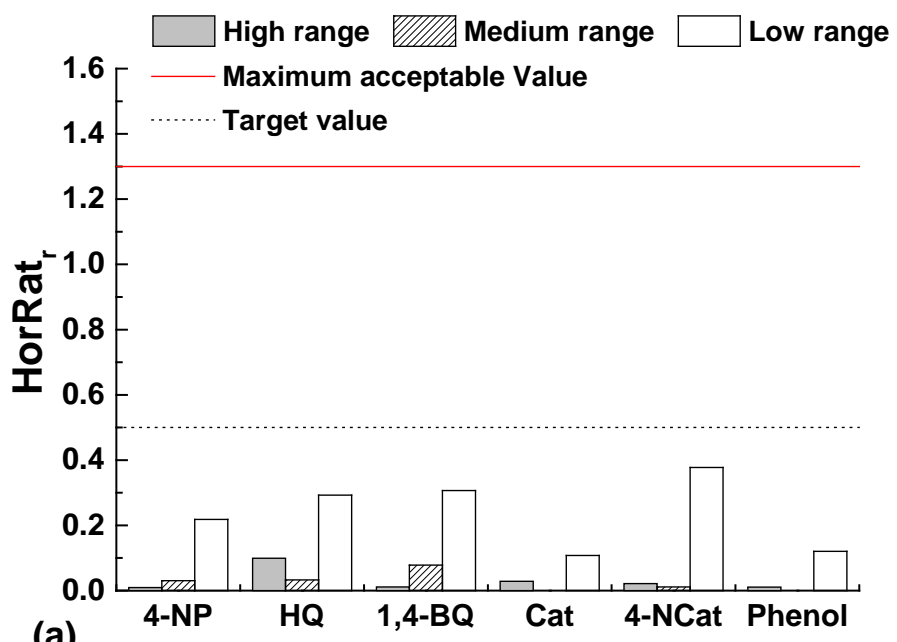

(a)

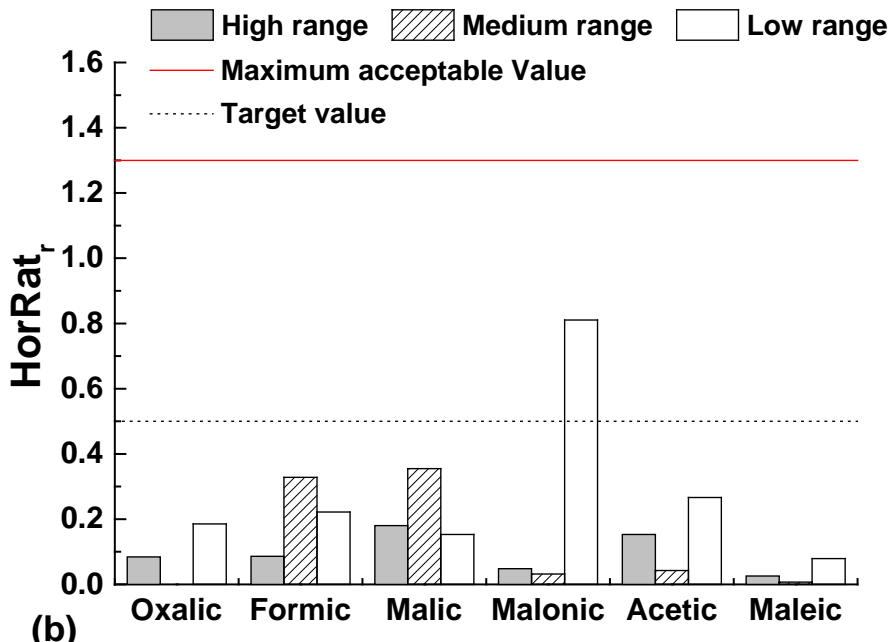

Figure 2: Horwitz ratios obtained in repeatability precision conditions (HorRatr), considering low, medium and high concentration levels over the linear range of (a) 4nitrophenol (4-NP) and aromatic intermediates [hydroquinone (HQ), 1,4-benzoquinone (1,4-BQ), catechol (Cat), 4-nitrocatechol (4-NCat) and phenol], and (b) carboxylic acids 


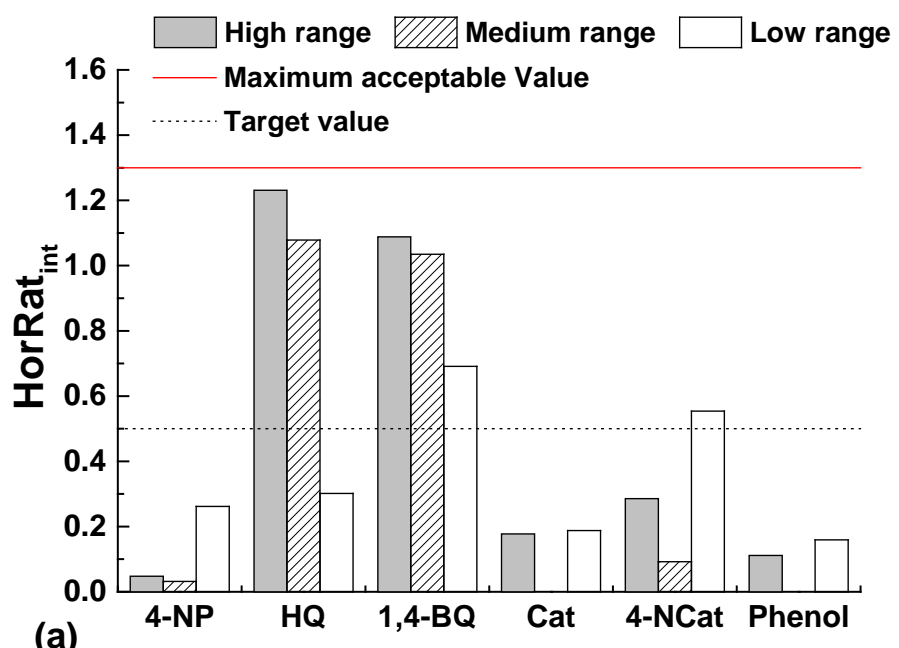

(a)

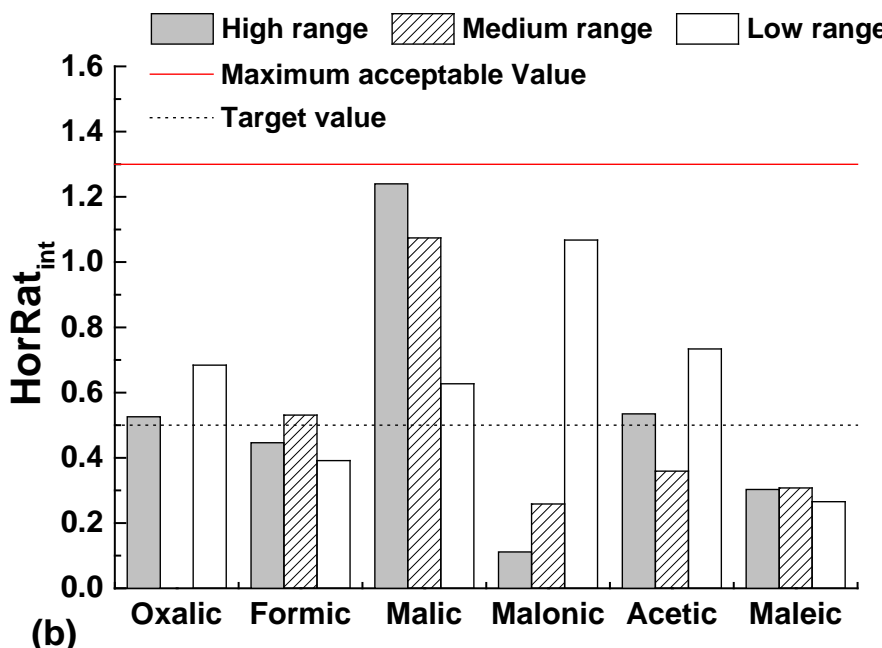

Figure 3: Horwitz ratios obtained in intermediate precision conditions (HorRatint), considering low, medium and high concentration levels over the linear range of (a) 4nitrophenol (4-NP) and aromatic intermediates [hydroquinone (HQ), 1,4-benzoquinone (1,4-BQ), catechol (Cat), 4-nitrocatechol (4-NCat) and phenol], and (b) carboxylic acids

\subsection{Application of the analytical methods}

So far, a single-component HPLC analytical method suitable for the determination of 4-NP was developed and validated throughout its linear range. Although the proficiency of this particular method has already been shown in the assessment of 4-NP abatement during CWPO experiments (Ribeiro et al 2015a), further studies were now performed. Specifically, three CWPO runs were carried out under the same operating conditions, in order to assess reproducibility and error of the 4-NP determinations. Through this approach, both the analytical error and CWPO process reproducibility were evaluated. The results obtained in this study are shown in Figure 4, where it is observed that the RSD of the individual measurements never reaches $3 \%$.

Likewise, the suitability of the two multi-component methods - one of which is devoted to the determination of possible aromatic intermediates, whereas the other is devoted to the determination of carboxylic acids - was already demonstrated in a previous work (Ribeiro et al 2015a). Figure 5 shows the oxidation/mineralization mechanism resulting from the CWPO of 4-NP, as previously proposed (Ribeiro et al 2015a), based on the application of the two analytical methods that were developed in this work. 


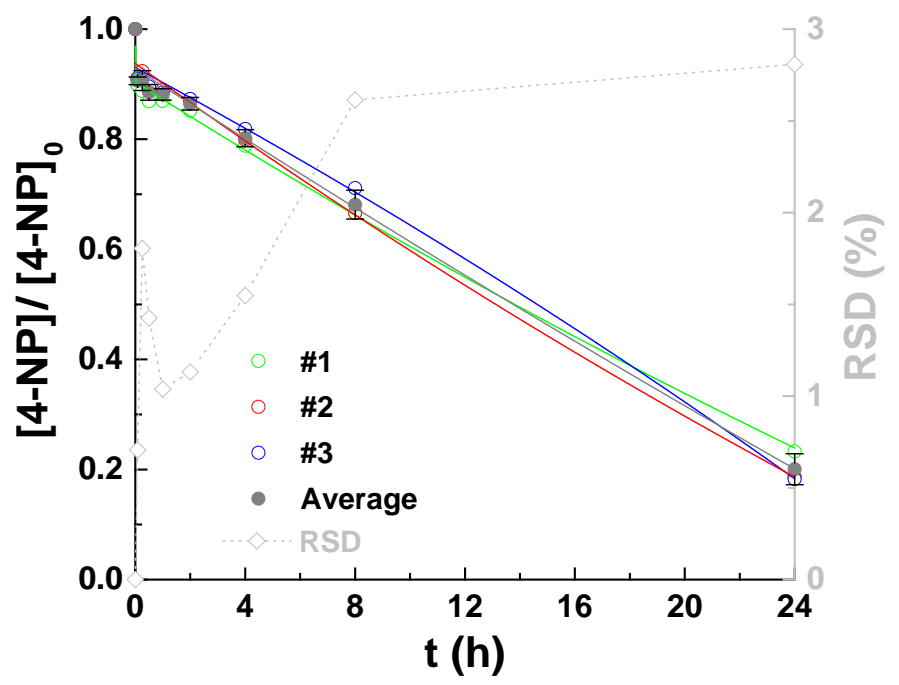

Figure 4: Reproducibility and error of 4-nitrophenol (4-NP, $\left.5 \mathrm{~g} \mathrm{~L}^{-1}\right)$ experimental values obtained in three independent CWPO runs performed with $\mathrm{CX} / \mathrm{Fe} 0.05\left(2.5 \mathrm{~g} \mathrm{~L}^{-1}\right)$, considering $\mathrm{T}=50^{\circ} \mathrm{C}, \mathrm{pH}=3$ and $\left[\mathrm{H}_{2} \mathrm{O}_{2}\right]_{0}=\left[\mathrm{H}_{2} \mathrm{O}_{2}\right]_{\text {stoichiometric }}=17.8 \mathrm{~g} \mathrm{~L}^{-1}$, as described in Section 2.5

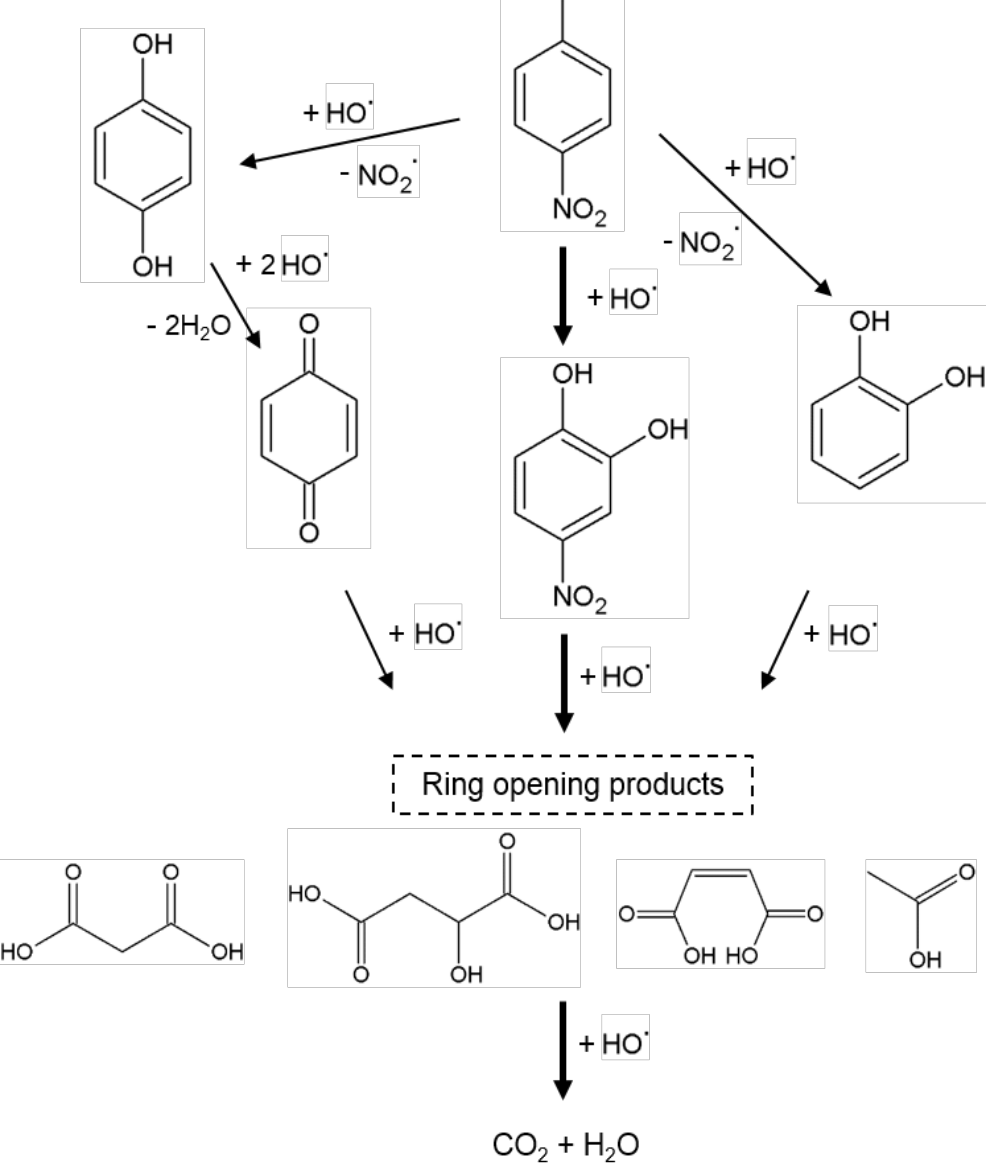

Figure 5: Mechanism proposed for the CWPO of 4-NP. Reprinted from (Ribeiro et al 2015a),

Copyright (C) 2014, with permission from Elsevier [License number: 3554781266494]

\section{Conclusions}

The main conclusion withdrawn from this work is that an analytical HPLC method for the determination of the 4-NP concentration in aqueous solutions was successfully developed and validated under the acceptance criteria that were previously established for this in-house pre- 
validation. The linearity of the calibration curve used for the determination of 4-NP was demonstrated through the Fisher's exact probability test. Accuracy studies have shown that the bias of this method is in the range $0.4-10 \%$, depending on the concentration level of the analyte. Repeatability precision and intermediate precision were also assessed in three concentration levels over the linear range, through the so-called Horwitz ratio (HorRat). In this case, HorRat values never exceeded 0.26, the maximum acceptable value being 1.3. Taking all this into account, the range of the analytical method developed for the determination of 4-NP was $0.0495-118.8 \mathrm{mg} \mathrm{L}^{-1}$. The CWPO process reproducibility was evaluated together with the analytical error of 4-NP determination. In this case, the sum of both contributions to error never reached $3 \%$.

Furthermore, two multi-component HPLC analytical methods were successfully developed for the determination of possible aromatic intermediates (i.e., hydroquinone, 1,4-benzoquinone, catechol, 4-nitrocatechol and phenol) and carboxylic acids (i.e., oxalic, formic, malic, malonic, acetic and maleic acids). These methods were validated in the linear range of each analyte, under the acceptance criteria that were previously established for this in-house prevalidation. In addition, the combination of these two analytical methods already led to the proposal of an oxidation/mineralization mechanism for the CWPO of 4-NP.

\section{References}

Apolinário, Ângela C., Adrián M.T. Silva, Bruno F. Machado, Helder T. Gomes, Paulo P. Araújo, José L. Figueiredo, and Joaquim L. Faria. 2008. "Wet air oxidation of nitro-aromatic compounds: Reactivity on single- and multi-component systems and surface chemistry studies with a carbon xerogel." Applied Catalysis B: Environmental no. 84 (1-2):75-86. DOI: 10.1016/j.apcatb.2007.12.018.

Bautista, Patricia, Ángel F. Mohedano, Nieves Menéndez, José A. Casas, and Juan J. Rodríguez. 2010. "Catalytic wet peroxide oxidation of cosmetic wastewaters with Fe-bearing catalysts." Catalysis Today no. 151 (1-2):148-152. DOI: 10.1016/j.cattod.2010.01.023.

Brown, Paula N., and Ronan Yu. 2013. "Determination of ginsenoside content in panax ginseng C.A. meyer and panax quinquefolius $L$. root materials and finished products by highperformance liquid chromatography with ultraviolet absorbance detection: Interlaboratory study." Journal of AOAC International no. 96 (1):12-19. DOI: 10.5740/jaoacint.12-153.

Christian, Gary D. 1994. Analytical chemistry. 5th ed. New York: John Wiley \& Sons, Inc.

Domínguez, Carmen M., Pilar Ocón, Asunción Quintanilla, José A. Casas, and Juan J. Rodriguez. 2013. "Highly efficient application of activated carbon as catalyst for wet peroxide oxidation." Applied Catalysis B: Environmental no. 140-141:663-670. DOI: 10.1016/j.apcatb.2013.04.068.

Domínguez, Carmen M., Pilar Ocón, Asunción Quintanilla, José A. Casas, and Juan J. Rodriguez. 2014a. "Graphite and carbon black materials as catalysts for wet peroxide oxidation." Applied Catalysis B: Environmental no. 144:599-606. DOI: 10.1016/j.apcatb.2013.07.069.

Domínguez, Carmen M., Asunción Quintanilla, José A. Casas, and Juan J. Rodriguez. 2014b. "Treatment of real winery wastewater by wet oxidation at mild temperature." Separation and Purification Technology no. 129:121-128. DOI: 10.1016/j.seppur.2014.04.003.

Fisher, R.A. . 1934. Statistical methods for research workers. Edited by F. A. E. Crew and D. Ward Cutler. 5th ed, Biological monographs and manuals. Edinburgh: Oliver and Boyd Ltd.

Gogate, Parag R., and Aniruddha B. Pandit. 2004. "A review of imperative technologies for wastewater treatment I: oxidation technologies at ambient conditions." Advances in Environmental Research no. 8 (3-4):501-551. DOI: 10.1016/S1093-0191(03)00032-7. 
High-performance liquid chromatography as a tool to evaluate the performance of the catalytic wet peroxide oxidation of 4-nitrophenol

Gomes, Helder T., Bruno F. Machado, Andreia Ribeiro, Ivo Moreira, Márcio Rosário, Adrián M.T. Silva, José L. Figueiredo, and Joaquim L. Faria. 2008. "Catalytic properties of carbon materials for wet oxidation of aniline." Journal of Hazardous Materials no. 159 (2-3):420426. DOI: 10.1016/j.jhazmat.2008.02.070.

Horwitz, William, and Richard Albert. 2006. "The Horwitz ratio (HorRat): a useful index of method performance with respect to precision." Journal of AOAC International no. 89 (4):1095-1109. PMID: 16915851.

Inchaurrondo, Natalia, Jorge O. Cechini, Josep Font, and Patricia Haure. 2012. "Strategies for enhanced CWPO of phenol solutions." Applied Catalysis B: Environmental no. 111-112:641648. DOI: 10.1016/j.apcatb.2011.11.019.

Indyk, Harvey E., Brendon D. Gill, Jane M. Broughton, and David C. Woollard. 2014. "Application of an LC-UV method to estimate lutein recovery during infant formula manufacture." International Dairy Journal no. 37 (2):82-86. DOI: 10.1016/j.idairyj.2014.02.010.

Latimer, George W. 2012. "Appendix F: guidelines for standard method performance requirements." In Official methods of analysis of AOAC International. ISBN: 0-935584-83-8: AOAC International.

Lindsay, Sandie 1992. High performance liquid chromatography. Edited by John Barnes. 2nd ed, Analytical chemistry by open learning. Chichester: John Wiley \& Sons Inc.

Loco, Joris Van, Marc Elskens, Christophe Croux, and Hedwig Beernaert. 2002. "Linearity of calibration curves: use and misuse of the correlation coefficient." Accreditation and Quality Assurance no. 7 (7):281-285. DOI: 10.1007/s00769-002-0487-6.

Lücking, F., Heinz Köser, Manfred Jank, and Anika Ritter. 1998. "Iron powder, graphite and activated carbon as catalysts for the oxidation of 4-chlorophenol with hydrogen peroxide in aqueous solution." Water Research no. 32 (9):2607-2614. DOI: 10.1016/S00431354(98)00016-5.

Meier, Peter C., and Richard E. Zünd. 2000. Statistical methods in analytical chemistry. Edited by J. D. Winefordner. 2nd ed, A series of monographs on analytical chemistry and its applications. New York: John Wiley \& Sons, Inc.

Melero, Juan A., Fernando Martínez, Juan A. Botas, Raúl Molina, and M. Isabel Pariente. 2009. "Heterogeneous catalytic wet peroxide oxidation systems for the treatment of an industrial pharmaceutical wastewater." Water Research no. 43 (16):4010-4018. DOI: 10.1016/j.watres.2009.04.012.

Navalon, Sergio, Mercedes Alvaro, and Hermenegildo Garcia. 2010. "Heterogeneous Fenton catalysts based on clays, silicas and zeolites." Applied Catalysis B: Environmental no. 99 (12):1-26. DOI: 10.1016/j.apcatb.2010.07.006.

Neamţu, Mariana, Carmen Zaharia, Cezar Catrinescu, Ayfer Yediler, Matei Macoveanu, and Antonius Kettrup. 2004. "Fe-exchanged $Y$ zeolite as catalyst for wet peroxide oxidation of reactive azo dye Procion Marine H-EXL." Applied Catalysis B: Environmental no. 48 (4):287294. DOI: 10.1016/j.apcatb.2003.11.005.

Peters, Frank T. , and Hans H. Maurer. 2005. "Bioanalytical method validation and its implications for forensic and clinical toxicology - A review." In Validation in chemical measurement. Berlin: Springer.

Pinho, Maria T., Helder T. Gomes, Rui S. Ribeiro, Joaquim L. Faria, and Adrián M.T. Silva. 2015. "Carbon nanotubes as catalysts for catalytic wet peroxide oxidation of highly concentrated phenol solutions: towards process intensification." Applied Catalysis B: Environmental no. 165:706-714. DOI: 10.1016/j.apcatb.2014.10.057. 
Ramirez, J. Herney, Carlos A. Costa, Luis M. Madeira, Guiomar Mata, Miguel A. Vicente, María L. Rojas-Cervantes, Antonio J. López-Peinado, and Rosa M. Martín-Aranda. 2007a. "Fentonlike oxidation of Orange II solutions using heterogeneous catalysts based on saponite clay." Applied Catalysis B: Environmental no. 71 (1-2):44-56. DOI: 10.1016/j.apcatb.2006.08.012.

Ramirez, J. Herney, Francisco J. Maldonado-Hódar, Agustín F. Pérez-Cadenas, Carlos MorenoCastilla, Carlos A. Costa, and Luis M. Madeira. 2007b. "Azo-dye Orange II degradation by heterogeneous Fenton-like reaction using carbon-Fe catalysts." Applied Catalysis B: Environmental no. 75 (3-4):312-323. DOI: 10.1016/j.apcatb.2007.05.003.

Rey, Ana, Marisol Faraldos, Ana Bahamonde, José A. Casas, Juan A. Zazo, and Juan J. Rodríguez. 2008. "Role of the activated carbon surface on catalytic wet peroxide oxidation." Industrial \& Engineering Chemistry Research no. 47 (21):8166-8174. DOI: 10.1021/ie800538t.

Ribeiro, Rui S., Nady A. Fathy, Amina A. Attia, Adrián M.T. Silva, Joaquim L. Faria, and Helder T. Gomes. 2012. "Activated carbon xerogels for the removal of the anionic azo dyes Orange II and Chromotrope 2R by adsorption and catalytic wet peroxide oxidation." Chemical Engineering Journal no. 195-196:112-121. DOI: 10.1016/j.cej.2012.04.065.

Ribeiro, Rui S., Adrián M.T. Silva, José L. Figueiredo, Joaquim L. Faria, and Helder T. Gomes. 2013a. "The influence of structure and surface chemistry of carbon materials on the decomposition of hydrogen peroxide." Carbon no. 62:97-108. DOI: 10.1016/j.carbon.2013.06.001.

Ribeiro, Rui S., Adrián M.T. Silva, José. L Figueiredo, Joaquim L. Faria, and Helder T. Gomes. 2013b. "Removal of 2-nitrophenol by catalytic wet peroxide oxidation using carbon materials with different morphological and chemical properties." Applied Catalysis B: Environmental no. 140:356-362. DOI: 10.1016/j.apcatb.2013.04.031.

Ribeiro, Rui S., Adrián M.T. Silva, Luisa M. Pastrana-Martínez, José L. Figueiredo, Joaquim L. Faria, and Helder T. Gomes. 2015a. "Graphene-based materials for the catalytic wet peroxide oxidation of highly concentrated 4-nitrophenol solutions." Catalysis Today, in press. DOI: 10.1016/j.cattod.2014.10.004.

Ribeiro, Rui S., Adrián M.T. Silva, Maria T. Pinho, José L. Figueiredo, Joaquim L. Faria, and Helder T. Gomes. 2015b. "Development of glycerol-based metal-free carbon materials for environmental catalytic applications." Catalysis Today no. 240, Part A:61-66. DOI: 10.1016/j.cattod.2014.03.048.

Rocha, Raquel P., Juliana P.S. Sousa, Adrián M.T. Silva, Manuel F.R. Pereira, and José L. Figueiredo. 2011. "Catalytic activity and stability of multiwalled carbon nanotubes in catalytic wet air oxidation of oxalic acid: The role of the basic nature induced by the surface chemistry." Applied Catalysis B: Environmental no. 104 (3-4):330-336. DOI: 10.1016/j.apcatb.2011.03.009.

Santos, Vera P., Manuel F.R. Pereira, P.C.C. Faria, and José J.M. Órfão. 2009. "Decolourisation of dye solutions by oxidation with $\mathrm{H}_{2} \mathrm{O}_{2}$ in the presence of modified activated carbons." Journal of Hazardous Materials no. 162 (2-3):736-742. DOI: 10.1016/j.jhazmat.2008.05.090.

Sasaki, Kazunori, Tomoyuki Oki, Toru Kobayashi, Yumi Kai, and Shigenori Okuno. 2014. "Singlelaboratory validation for the determination of caffeic acid and seven caffeoylquinic acids in sweet potato leaves." Bioscience, Biotechnology, and Biochemistry no. 78 (12):2073-2080. DOI: 10.1080/09168451.2014.942253.

Snyder, Lloyd R., Joseph J. Kirkland, and Joseph L. Glajch. 1997. Practical HPLC method development. 2nd ed. Hoboken: John Wiley \& Sons, Inc. 
Taran, Oxana, Elena Polyanskaya, Olga Ogorodnikova, Vladimir Kuznetsov, Valentin Parmon, Michèle Besson, and Claude Descorme. 2010. "Influence of the morphology and the surface chemistry of carbons on their catalytic performances in the catalytic wet peroxide oxidation of organic contaminants." Applied Catalysis A: General no. 387 (1-2):55-66. DOI: 10.1016/j.apcata.2010.08.001.

Taverniers, Isabel, Marc De Loose, and Erik Van Bockstaele. 2004. "Trends in quality in the analytical laboratory. II. Analytical method validation and quality assurance." Trends in Analytical Chemistry no. 23 (8):535-552. DOI: 10.1016/j.trac.2004.04.001.

UNODC. 2009. Guidance for the validation of analytical methodology and calibration of equipment used for testing of illicit drugs in seized materials and biological specimens. New York: United Nations Office on Drugs and Crime (UNODC).

USEPA. 1997. Recommended guidelines for measuring organic compounds in puget sound water, sediment and tissue samples. Seattle: U. S. Environmental Protection Agency (USEAP).

Yang, Libo , Li Liu, Bernard A. Olsen, and Mark A. Nussbaum. 2000. "The determination of oxalic acid, oxamic acid, and oxamide in a drug substance by ion-exclusion chromatography." Journal of Pharmaceutical and Biomedical Analysis no. 22 (3):487-493. DOI: 10.1016/S0731-7085(00)00230-2.

\section{Acknowledgments}

Work supported by project PEst-C/EQB/LA0020/2013, co-financed by FEDER through COMPETE, QREN and ON2, and by FCT - Fundação para a Ciência e a Tecnologia. Rui S. Ribeiro acknowledges financial support from the FCT individual Ph.D. grant SFRH/BD/94177/2013. Adrián M.T. Silva acknowledges the FCT Investigator 2013 Programme (IF/01501/2013), with financing from the European Social Fund and the Human Potential Operational Programme. 